\title{
The Applied Mathematical Simulation Modeling Algorithm for a Multi Aircraft Landing Dynamic System at Bujumbura International Airport Mathematics and Innovative Technologies in Africa
}

\author{
F. Nahayo, \\ ISTA -LURMISTA-FS-CRMP, University of Burundi, Burundi \\ J. Ndimubandi, \\ FS-CRMP, University of Burundi, Burundi
}

A. Manirabona,

A. Niyongere,

FSI-CRIET, University of Burundi, Burundi

Doi:10.19044/esj.2019.v15n30p495 URL:http://dx.doi.org/10.19044/esj.2019.v15n30p495

\begin{abstract}
The aim of this paper is to set up an efficient nonlinear application algorithm simulation model for a multi aircraft landing dynamic system in one Runway when considering Bujumbura International Airport. The mathematical modelization of the solved problem is a non-convex optimal control governed by ordinary non-linear differential equations. The dynamic programming technic is applied because it is a sufficiently high order and it does-not require computation of the partial derivatives of the aircraft dynamic. This application is be coded with Linux operating system, but it can also be run on the windows system. High runing performance are obtained with results giving feasible trajectories with a robust optimizing of the objective function. The user interfaces designed in Glade are saved as XML, and by using the GtkBuilder GTK+ object these can be loaded by applications dynamically as needed. By using GtkBuilder, Glade XML files can be used in numerous programming languages including $\mathrm{C}, \mathrm{C}++, \mathrm{C \#}$, Java, Perl, Python, AMPL,etc.. Glade is Free Software released under the GNU GPL License. The algorithm is implemented when considering discrete mathematics while using Bujumbura International Airport Geographic Information System.
\end{abstract}

Keywords: Aircraft Landing Dynamic System, Optimal Control, Dynamic Programming, GUI GPL Application 00AIRLADY S R2018A +00 


\section{Introduction}

In this work, an efficient nonlinear application algorithm simulation model for a multi aircraft landing dynamic system is developped while maintaining a reliable evolution of the flight procedures of aircraft dynamic system on approach. The aircraft are landing successively on one runway without conflict (E. Roux, 2006).

The model considered here is non-convex and non-linear optimal control problem leading to a system of non-linear ordinary differential equations (I. Chryssoverghi\& J. Colestos and B. Kokkinis, 2007). The aircraft dynamic is described by a three dimensional set of non-linear ordinary differential equations subjected to state and control constraints. The functional to be minimized describes the overall levels of noise collected on the ground, emitted by the aircraft. The formulation of the problem takes into account several kinds of constraints such as aircraft stability, performance and flight safety. Programming technic is applied through the Nonlinear Interior point Trust Region Optimization solver 'KNITRO'(Waltz,2008) with a Modeling Language for Mathematical Programming 'AMPL'(R.Fourer, 2003). This application will be coded with Linux system on 64 bit operating system. High runing performances are obtained with results giving feasible trajectories with a robust optimizing of the objective function. The user interfaces is designed in Glade by using the GtkBuilder GTK+ object and this can be loaded by applications dynamically as needed.

\section{The Bujumbura International Airport Traffic}

Bujumbura International Airport (IATA: BJM, ICAO: HBBA) is an airport in Bujumbura, the former capital of Burundi. It is Burundi's only international airport and the only one with a paved runway. Opened in 1952, the airport turned 67 years old on December 5th 2019. 


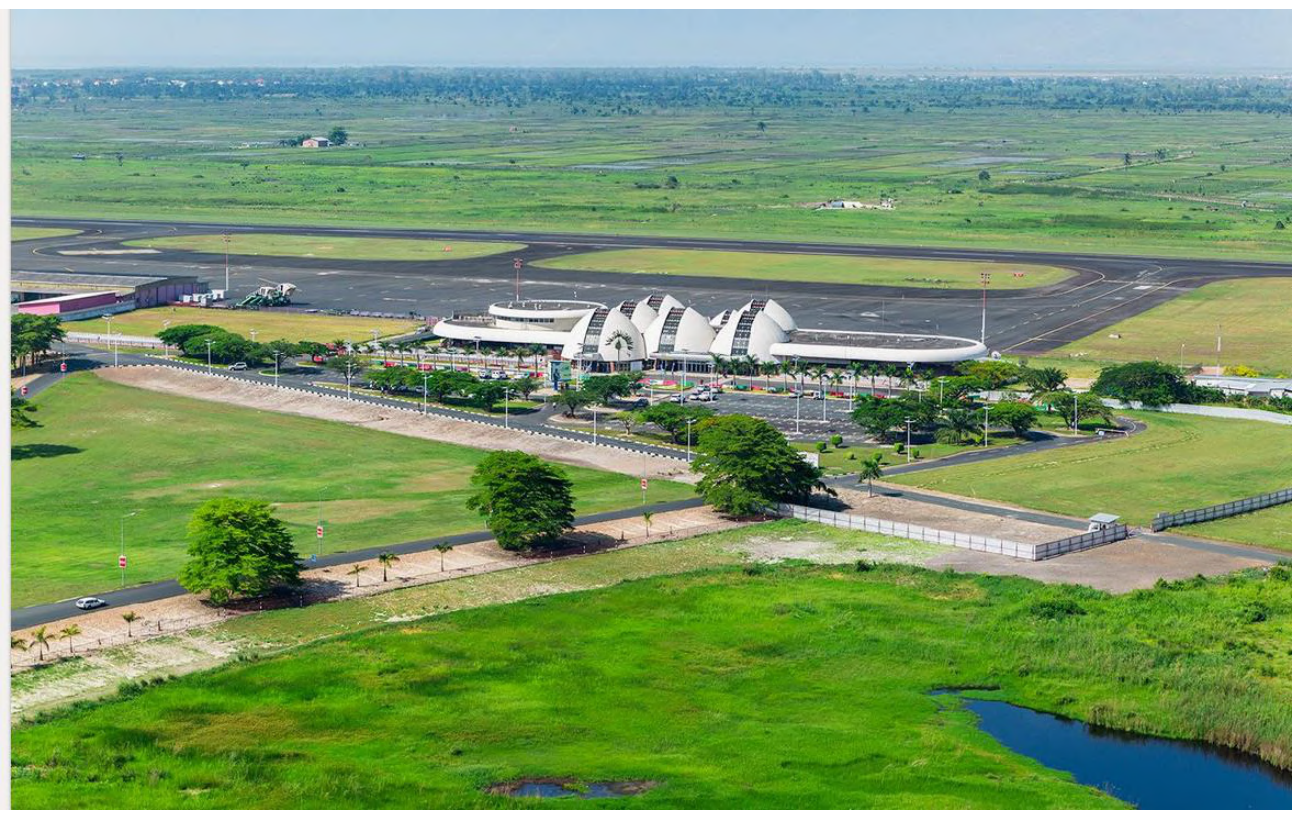

Figure 1. Spatial view of Bujumbura International Airport

As of December 2018, the following airlines maintain regular scheduled service to Bujumbura International Airport: [2]

\begin{tabular}{|l|l|l|}
\hline $\begin{array}{l}\text { Bujumbura Aerospace Regular } \\
\text { Traffic }\end{array}$ & Airlines & Destinations \\
\hline Departures and Arrivals flights & Air Tanzania & Dar es Salaam, Kigoma \\
\hline & Brussels Airlines & Brussels1 \\
\hline & Ethiopian Airlines & Addis Ababa, Kigali \\
\hline & Kenya Airways & Kigali,Nairobi-Jomo Kenyatta \\
\hline & RwandAir & Kigali \\
\hline
\end{tabular}

Note 1: Brussels Airlines' outbound ights stop in Entebbe, while all inbound rights are nonstop. The airline does not have trac rights to transport passengers solely between Bujumbura and Entebbe. 


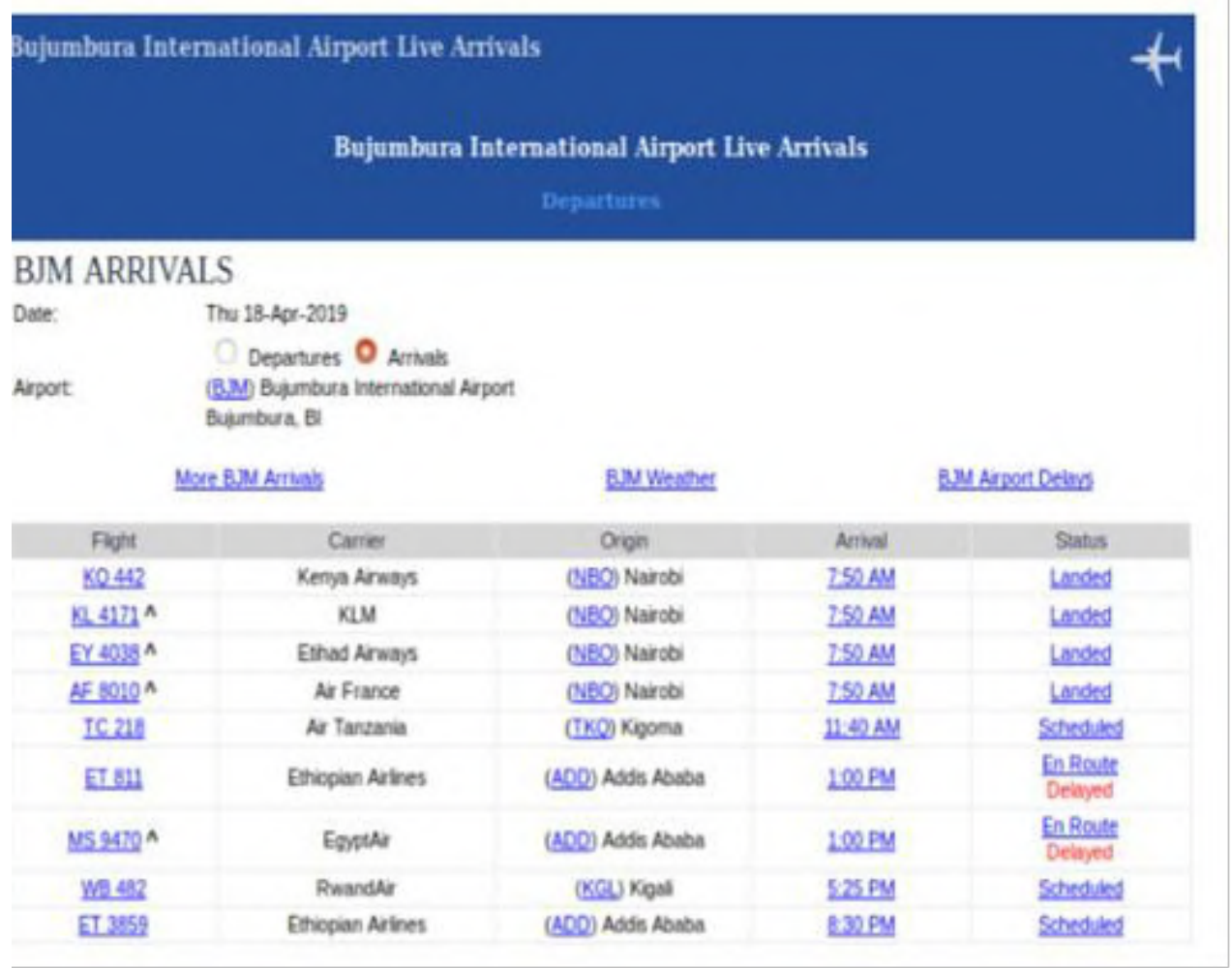

Figure 2. Bujumbura International Airport Live arrivals on 18 April 2019.

\section{Mathematical modeling of the aircraft dynamic system}

The design of an aircraft is an excellent non-linear optimization model. From conception to piloting, several disciplines are present. We cite aerodynamics, propulsion, structural mechanics, performance calculations, energetics, acoustics, and many others.

A moving airplane is therefore a complex dynamic system, difficult to study in all its generality. The large number of disciplines involved in both the design and operation of the aircraft makes it a complex process.

The various parameters involved in this process are either managed by a single discipline or shared. Thus, several interactions between these disciplines translate a coupling of which the results of one can be used for the parameters of the others. Unfortunately, the objectives of each discipline are often contradictory. It is then necessary to develop optimization techniques to effectively integrate the methods developed by each of the disciplines involved in order to seek a global optimun. In this section, we return to the optimal control of a commercial airplane while keeping the aerodynamic performances (F.Nahayo,2017). The flight dynamics of a commercial aircraft is a very complicated subject when it is combined with the analysis and 
optimization of the aircraft's behavior (S.Khardi F. Nahayo and M. Haddou, 2011).

In this paragraph, it is a question of going back on the threedimensional dynamic model of a civil plane, the analysis of these operational performances and quality of flight. The modeling of the aerodynamic, propulsive and mass forces of a commercial aircraft is the basis of the flight dynamics of this one. The analysis of these processes focuses mainly on the sciences of mechanical and automatic control. The following figure illustrates the functional organization of aircraft flight dynamics (Boiffier, 1999 and Boiffier, 2001).

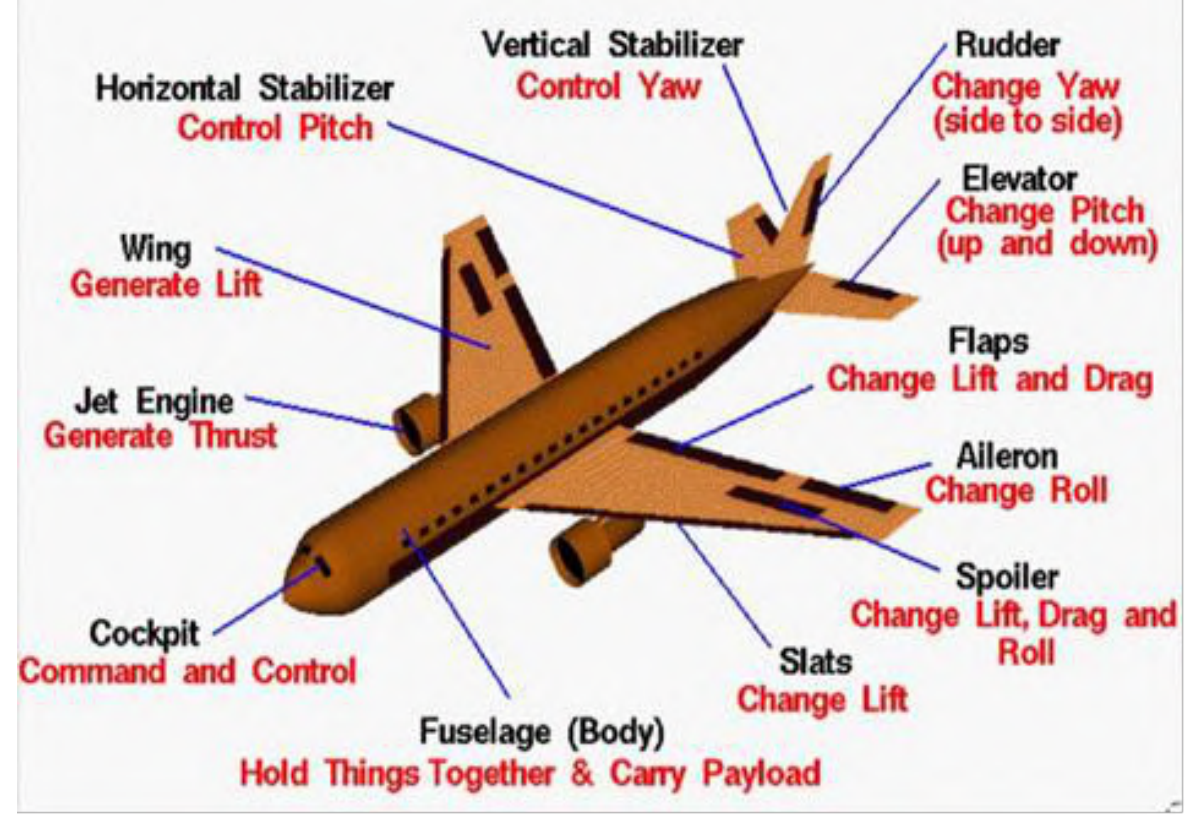

Figure 3. A300 Aircraft Structure, Design Modeling and Parts Functions. 


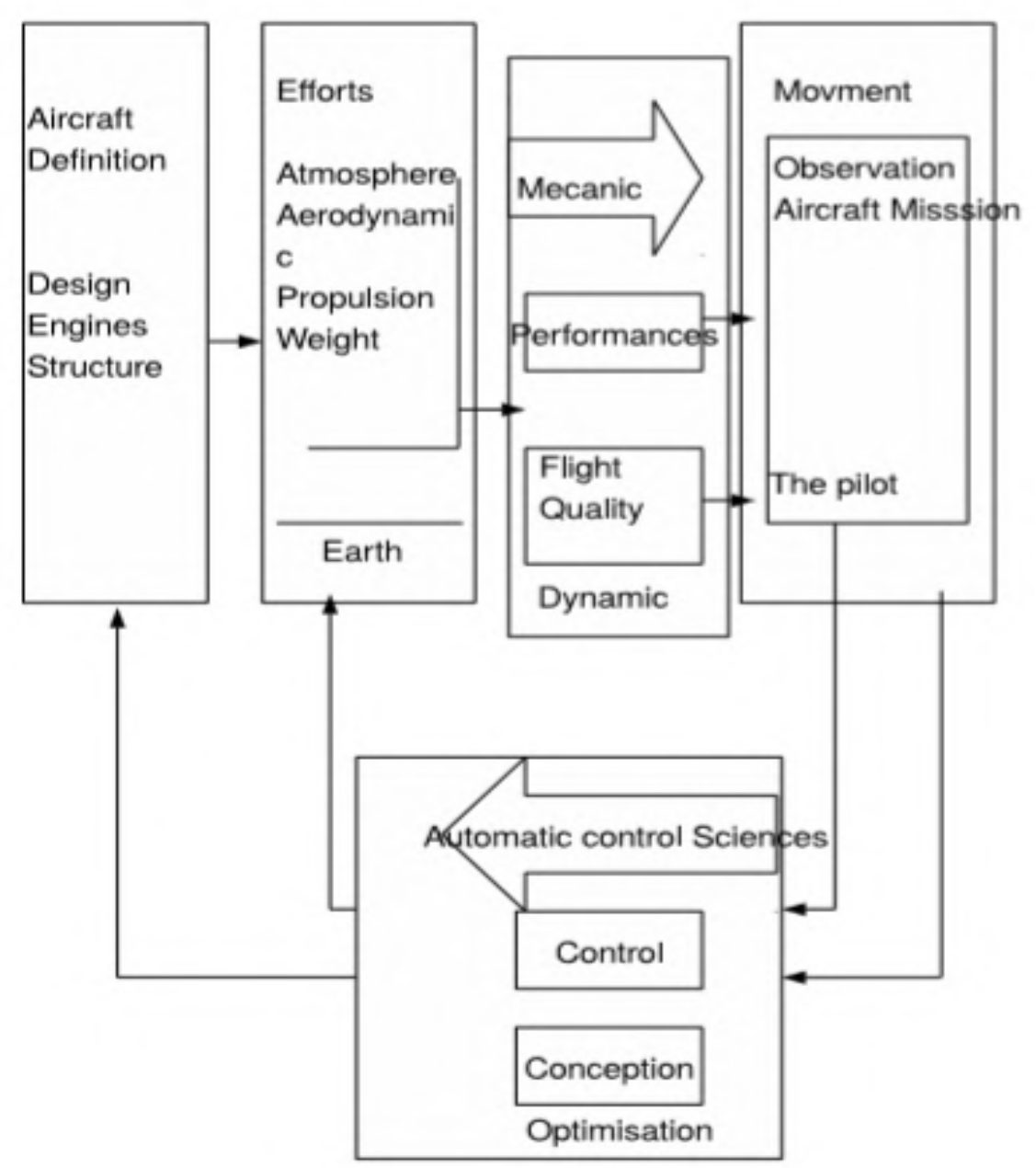

Figure 4. Aircraft control dynamic function modeling

The figure 4 show the the functional organization of aircraft ight dynamics when considering the the aircraft design, effort, dynamic, mouvement and the automaticcontrol sciences. The aircraft model considered is Airbus A300 which transport a maximum of 266 passengers when the maximum weight is about $171000 \mathrm{Kg}$ on the take off procedure.

\subsection{Aircraft dynamic equations}

The equations of 3D-motion of each aircraft $A_{i}, i \in\{1,2\}$ read (F.Nahayo, 2012, Boier, 1999 and K. Blin 2000): 


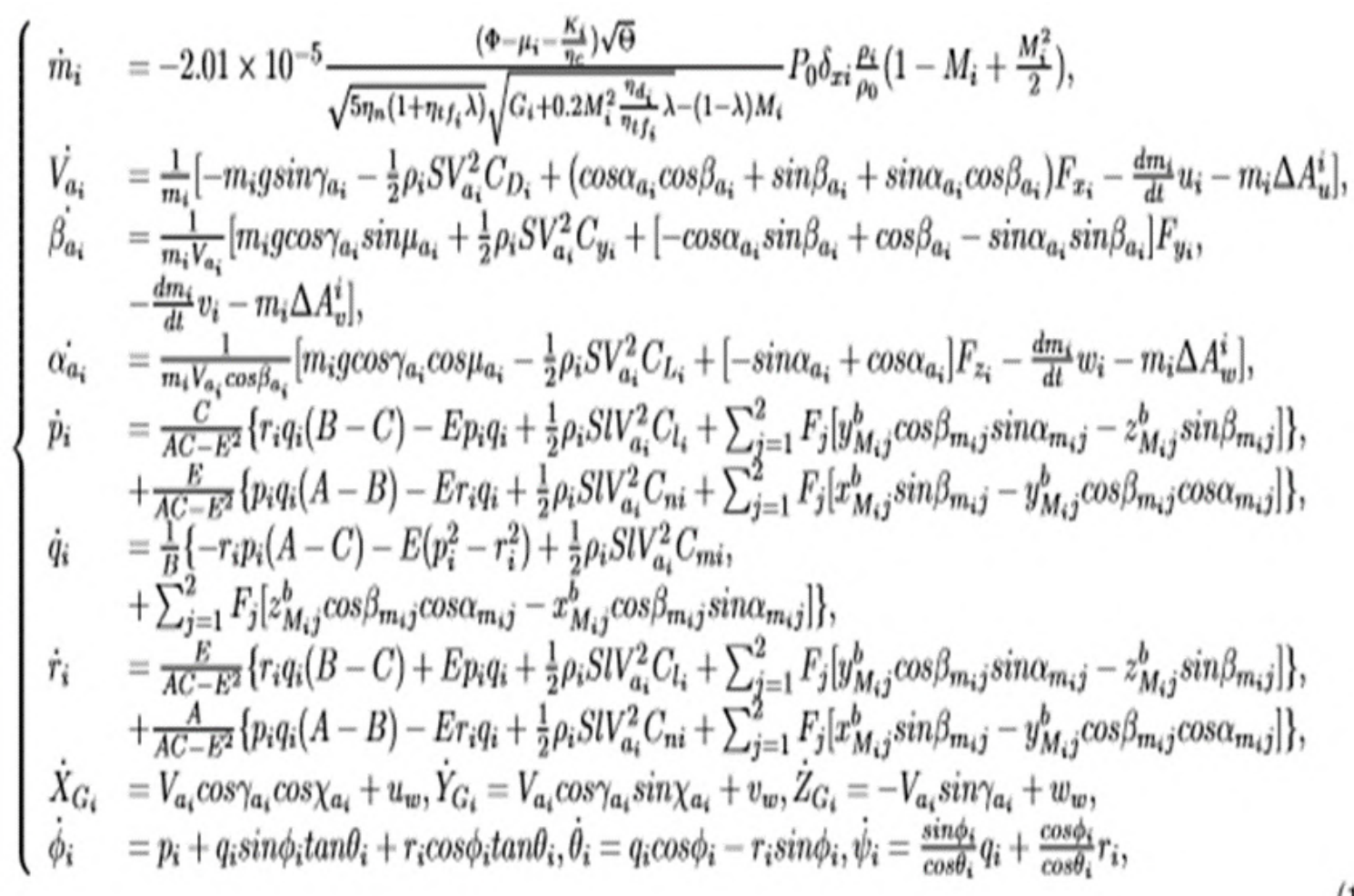

where $\mathrm{j} \in\{1,2\}$ stands for the first and second engine of each aircraft i, the expressions $A=I_{x x}, B=I_{y y}, C=I_{z z}, E=I_{x z}$ are the inertia moments of the aircraft, $\rho_{i}$ is the air density, $\mathrm{S}$ is the aircraft reference area, 1 is the aircraft reference length, $\mathrm{g}$ is the acceleration due to gravity, $C_{D i}=C_{D o}+k C_{L i}^{2}$ is the drag coefficient, $\quad C_{y i}=C_{y \beta} \beta+C_{y p} \frac{p l}{V}+C_{y r} \frac{r l}{V}+C_{Y \delta i} \delta_{l i}+C_{Y \delta n} \delta_{n i}$ is the lateral forces coefficient, $C_{L i}=C_{L \alpha}\left(\alpha_{a}-\alpha_{a o}\right)+C_{L \delta_{m i}} \delta m i+C_{L M} M_{i}+C_{L q} \frac{q_{0}^{b}}{V}$ is the lift coefficient, $C_{l i}=C_{l \beta} \beta+C_{l p} \frac{p l}{V}+C_{l r} \frac{r l}{V}+C_{l \delta i} \delta_{l i}+C_{l \delta n} \delta_{n i} \quad$ is the rolling moment coefficient, $C_{m i}=C_{m 0}+C_{m \alpha}\left(\alpha-\alpha_{0}\right)+C_{m \delta m} \delta_{m i}$ is the pitching moment coefficient, $\quad C_{n i}=C_{n \beta} \beta+C_{n p} \frac{p l}{V}+C_{n r} \frac{r l}{V}+C_{n \delta i} \delta_{l i}$ is the yawing moment coefficient, $\left(x_{M i j}^{b}, x_{M i j}^{b}, x_{M i j}^{b}\right)$ is the position of the engine in the body frame, $P_{0}$ is the full thrust, $\rho_{0}$ is the atmospheric density at the ground, $F=\left(F_{x i}, F_{y i}, F_{z i}\right)$ is the propulsive force, $V_{\alpha i}=\left(u_{i}, v_{i}, w_{i}\right)$ is the aerodynamic speed, 
$\left(\Delta A_{u}^{i}, \Delta A_{v}^{i}, \Delta A_{w}^{i}\right)$ is the complementary acceleration, $\left(u_{w}, v_{v}, w_{w}\right)$, is the wind velocity, $\beta_{m i j}$ is the yaw setting of the engine and $\alpha_{m i j}$ is the pitch setting of the engine. The mass change is reflected in the aircraft fuel consumption as described by E. Torenbeek (E. Roux 2005) where the specific consumption is $C_{S R i}=2.01 \times 10^{-5} \frac{\left(\Phi-\mu_{i}-\frac{\kappa_{i}}{\eta_{c}}\right) \sqrt{\Theta}}{\sqrt{5 \eta_{n}\left(1+\eta_{t f_{i}} \lambda\right)} \sqrt{G_{i}+0.2 M_{i}^{2} \frac{\eta_{d i}}{\eta_{t f i}} \lambda-(1-\lambda) M_{i}}}$ with the generating function

$$
\begin{aligned}
& G_{i}=\left(\Phi-\frac{K_{i}}{\eta_{c}}\right)\left(1-\frac{1.01}{\eta_{i}^{\frac{v-1}{v}}\left(K_{i}+\mu_{i}\right)\left(1-\frac{K_{i}}{\Phi \eta_{c} \eta_{t}}\right)}\right), K_{i}=\mu_{i}\left(\varepsilon_{c}^{\frac{v-1}{v}}-1\right), \\
& \mu_{i}=1+\frac{v-1}{2} M_{i}^{2}
\end{aligned}
$$

The nomenclature of engine performance variables are given by $G_{i}$ the gas generator power function, $G_{0}$ the gas generator power function (static, sea level), $\mathrm{K}$ the temperature function of compression process, $M_{i}$ the flight Mach number, $T_{4}$ the turbine Entry total Temperature, $T_{0}$ the ambient temperature at sea level, $\mathrm{T}$ the flight temperature, while the nomenclature of engines yields is $\eta_{c}=0.85$ the isentropic compressor efficiency, $\eta_{d_{i}}=1-1.3\left(\frac{0.05}{\operatorname{Re} \delta}\right)^{2}\left(\frac{0.5}{M_{i}}\right)^{2} \frac{L}{D}$, the isentropic fan intake duct efficiency, L the duct length, D the inlet diameter, $\mathrm{Re}$ the Reynolds number at the entrance of the nozzle, $\eta_{f_{i}}=0.86-3.13 \times 10^{-2} M_{i}$ the isentropic fan efficiency, $\eta_{i}=\frac{1+\eta_{d_{i}} \frac{x-1}{2} M_{i}^{2}}{1+\frac{x-1}{2} M_{i}^{2}}$ the gas generator intake stagnation pressure ratio, $\eta_{n}=0.97 \eta$ the isentropic efficiency of expansion process in nozzle, $\eta_{t}=0.88$ the isentropic turbine efficiency $\eta_{t} \eta_{f_{i}}, \varepsilon_{c}$ the overall pressure ratio (compressor), $v$ the ratio of specific heats $v=1.4, \lambda$ the bypass ratio, $\mu_{i}$ the ratio of stagnation to static temperature of ambient air, $\Phi$ the nondimensional turbine entry temperature $\Phi=\frac{T_{4}}{T}$ and $\Theta$ 
the relative ambient temperature $\Theta=\frac{T}{T_{0}}$. The expressions $\alpha_{a i}(t), \beta_{a i}(t), \theta_{i}(t), \psi_{i}(t), \phi_{i}(t), V_{a i}(t), X_{G i}(t), Y_{G i}(t), Z_{q i}(t), p_{i}(t), q_{i}(t), r_{i}(t), m_{i}(t)$ are respectively the attack angle, the aerodynamic sideslip angle, the inclination angle, the cup, the roll angle, the airspeed, the position vectors, the roll velocity of the aircraft relative to the earth, the pitch velocity of the aircraft relative to the earth, the yaw velocity of the aircraft relative to the earth and the aircraft mass. The system (1) could be written in a simplified form $\frac{d y_{i}(t)}{d t}=f_{i}\left(y_{i}(t), u_{i}(t)\right)$, $y_{i}(t)=\left(\alpha_{a i}(t), \beta_{a i}(t), \theta_{a i}(t), \psi_{a i}(t), \phi_{i}(t), V_{a i}(t), X_{G I}(t), Y_{G i}(t), Z_{G i}(t), p_{i}(t), q_{i}(t), r_{i}(t), m_{i}(t)\right)($ $u_{i}(t)=\left(\delta_{l i}(t), \delta_{m i}(t), \delta_{n i}(t), \delta_{x i}(t)\right)$

henceforth $y_{i}$ is called a state function and the expressions $\delta_{l i}(t), \delta_{m i}(t), \delta_{n i}(t), \delta_{x i}(t)$ are respectively the roll control, the pitch control, the yaw control and the thrust control. The dynamics relationship can be written as : $\dot{y}_{i}(t)=f_{i}\left(y_{i}, u_{i}, t\right), \forall t \in[0, T], y_{i}(0)=y_{i o}$.

\subsection{The optimal objective function model}

Let us define the quantity named the Sound Exposure Level 'SEL' (F. Nahayo 2012, L.Abdallah 2007, M-M. Harris and E. Mary, D. Martin 2000), $S E L=10 \log \left[\int_{\dot{t}^{\prime}} 10.1 L_{A 1(t)}\right]$ where $t^{\prime}$ is the noise event interval. $\left[t_{10}, t_{1 f}\right]$ and $\left[t_{20}, t_{2 f} \mid\right.$ are the respective approach intervals for the first and second aircraft, the objective function is calculated as

$$
\begin{aligned}
& S E L_{G}=10 \log \left\{\frac { 1 } { t _ { 2 f } - t _ { 1 0 } } \left[\left(t_{20}-t_{10}\right) \int_{t_{10}}^{t_{20}} 10{ }^{0.1 L} A 1(t) d t\right.\right. \\
& +\left(t_{1 f}-t_{20}\right) \int_{t_{20}}^{t_{1 f}} 10^{0.1 L} A 1(t) d t+\left(t_{1 f}-t_{20}\right) \int_{t_{10}}^{t_{1 f}} 10^{0.1 L} A 2(t) d t
\end{aligned}
$$

where the cost function SELG is the cumulated two-aircraft noise. Expressions $L_{A 1}(t), L_{A 2}(t)$ are equivalent and reflect the aircraft jet noise given by the formula (L. Abdallah 2007, R. James Stone \& D.E. Groesbeck\& C.L Zola,1991): 


$$
\begin{aligned}
& L_{A_{1}}(t)=141+\log \left(\frac{\rho_{1}}{\rho_{i}}\right)^{w}+10 \log \left(\frac{V_{e}}{c}\right)^{7.5}+10 \log s_{1}+3 \log \left(\frac{2 s_{1}}{\pi d_{i}^{2}}+0.5\right) \\
& +5 \log \frac{\tau_{1}}{\tau_{2}}+10 \log \left[\left(1-\frac{v_{2}}{v_{1}}\right)^{m e}+1.2 \frac{\left(1+\frac{s_{2} v_{2}^{2}}{s_{1} v_{1}^{2}}\right)^{4}}{\left(1+\frac{s_{2}}{s_{1}}\right)^{3}}\right]-20 \log R+\Delta V \\
& +10 \log \left[\left(\frac{\rho_{i}}{\rho_{I S A}}\right)^{2}\left(\frac{c}{c_{I S A}}\right)^{4}\right]
\end{aligned}
$$

where $v_{1}$ is the jet speed at the entrance of the nozzle, $v_{2}$ the jet speed at the nozzle exit, $\tau_{1}$ the inlet temperature of the nozzle, $\tau_{2}$ the temperature at the nozzle exit, $\rho_{i}$ the density of air, $\rho_{1}$ the atmospheric density at the entrance of the nozzle, $\rho_{I S A}$ the atmospheric density at ground, $s_{1}$ the entrance area of the nozzle hydraulic engine, $s_{2}$ the emitting surface of the nozzle hydraulic engine, $d_{1}$ the inlet diameter of the nozzle hydraulic engine, $V_{e}=v_{1}\left[1-\left(\frac{V}{v_{1}}\right) \cos \left(\alpha_{p}\right)\right]^{\frac{2}{3}}$ the effective speed $\left(\alpha_{p}\right.$ is the angle between the axis of the motor and the axis of the aircraft), $\mathrm{R}$ the source observer distance, $w$ the exponent variable defined by $w=\frac{3\left(\frac{V_{e}}{c}\right)^{3.5}}{0.6+\left(\frac{V_{e}}{c}\right)^{3.5}}-1$ the sound velocity $(\mathrm{m} / \mathrm{s})$, me the exhibiting variable depending on the type of aircraft: $m e=1.1 \sqrt{\frac{s_{2}}{s_{1}}}, \frac{s_{2}}{s_{1}}<29.7 ; m e=6.0, \frac{s_{2}}{s_{1}} \geq 29.7$,

the term $\Delta V=-15 \log \left(C_{D}\left(M_{c}, \theta\right)\right)-10 \log (1-M \cos \theta)$, means the Doppler convection when $C_{D}\left(M_{c}, \theta\right)=\left[\left(1+M_{c} \cos \theta\right)^{2}+0.04 M_{c}^{2}\right], \quad M$ the aircraft Mach Number, $M_{c}$ the convection Mach Number: $M_{c}=0.62\left(v_{1}-V \cos \left(\alpha_{p}\right)\right) / c$ is the Beam angle. The objective formula above could be written in the following simplified form $J_{G 12}(y(),. u())=.\int_{t^{\prime}} g(y(t), u(t)) d t$. 


\subsection{Constraints}

The considered constraints concern aircraft flight speeds and altitudes, flight angles and control positions, energy constraint, aircraft separation, flight velocities of aircraft relative to the earth and the aircraft mass(J.L.Boiffier 1999, Ifrance 2000):

(1) The vertical separation given by $Z_{G 12}=Z_{G 2}-Z_{G 1}$ where $Z_{G 1}-Z_{G 2}$ are respectively the altitude of the first and the second aircraft and $Z_{G_{12}}$ the altitude separation.

(2) The horizontal separation $X_{G 12}=X_{G 1}-X_{G 2}[13,14,38]$ where $X_{G 1}, X_{G 2}$ are horizontal position of the first and the second aircraft and their distance.

(3) The aircraft speed $V_{a i}$ must be bounded as follows $1.3 V_{s} \leq V_{a i} \leq V_{i f}$ aircraft where $V_{s}$ is the stall speed, $V_{i f}$ is the maximum speed and $V_{i o}=1.3 V_{s}$, the minimum speed of the aircraft $A_{i}[15,36]$, the roll velocity of the aircraft relative to the earth $p_{i} \in\left\lfloor p_{i o}, p_{i f}\right\rfloor$ the pitch velocity of the aircraft relative to the earth $q_{i} \in\left\lfloor q_{i o}, q_{i f}\right\rfloor$ and the yaw velocity of the aircraft relative to the earth $r_{i} \in\left\lfloor r_{i o}, r_{i f}\right\rfloor$.

(4) On the approach, the ICAO standards and aircraft manufacturers require flight angle evolution as follows attack angle $\alpha_{a i} \in\left\lfloor\alpha_{i o}, \alpha_{i f}\right\rfloor$,the inclination angle $\theta_{i} \in\left\lfloor\theta_{i o}, \theta_{i f}\right\rfloor$ and the roll angle $\phi_{i} \in\left\lfloor\phi_{i o}, \phi_{i f}\right\rfloor$.

(5) The aircraft control $\delta(t)=\left(\delta_{l i}(t), \delta_{n i}(t), \delta_{x i}(t)\right)$ keeps and still between the position $\delta_{\text {lio }}$ and $\delta_{\text {lif }}$ for the roll control $\delta_{\text {mio }}$ and $\delta_{\text {mif }}$ for the pitch control $\delta_{\text {nio }}$ and $\delta_{n i f}$ for the yaw control and $\delta_{x i o}$ and $\delta_{x i f}$ for the thrust.

(6) The mass $m_{i}$ of the aircraft $A_{i}$ is variable: $m_{i o}<m_{i}<m_{i j}, i=1.2$. This constraint results in energy consumption of the aircraft $[8,24]$.

On the whole, the constraints come together under the relationship $k_{l i}\left(y_{i}, u_{i}\right) \leq 0, k_{2 i}\left(y_{i}, u_{i}\right) \geq 0$, where

$k_{1 i}\left(y_{i}, u_{i}\right)=\left(\alpha_{i}(t)-\alpha_{i f}, \theta_{i}(t)-\theta_{i f}, \psi_{i}(t)-\psi_{i f}, \phi_{i}(t)-\phi_{i f}, V_{a i}(t)-V_{a i f}, X_{G i}(t)-X_{G i f}\right.$, $\left.\delta_{m i}(t)-\delta_{m i f}, \delta_{n i}(t)-\delta_{n i f}, \delta_{x i}(t)-\delta_{x i f}, m_{i}(t)-m_{i f}\right)$;

$k_{2 i}\left(y_{i}, u_{i}\right)=\left(\alpha_{i}(t)-\alpha_{i o}, \theta_{i}(t)-\theta_{i o}, \psi_{i}(t)-\psi_{i o}, \phi_{i}(t)-\phi_{i o}, V_{a i}(t)-V_{a i o}\right.$,

$X_{G i}(t)-X_{G i o}$.

$Y_{G i}(t)-Y_{G i o}, Z_{G i}(t)-Z_{G i o}, p_{i}(t)-p_{i o}, q_{i}(t)-q_{i o}, r_{i}(t)-r_{i o}, \delta_{l i}(t)-\delta_{l i o}$,

$\left.\delta_{m i}(t)-\delta_{m i o}, \delta_{n i}(t)-\delta_{n i o}, \delta_{x i}(t)-\delta_{x i o}, m_{i}(t)-m_{i o}\right)$ 


\subsection{The aircraft optimal control problem}

The combination of the aircraft dynamic equation, the aircraft objective function and the aircraft flight constraints, the two-aircraft acoustic optimal control problem is given as follows:

$$
\left\{\begin{array}{l}
\min _{\mathbf{u} \in \mathbf{U}} J_{G 12}(\mathbf{y}(.), \mathbf{u}(.))=\int_{t 10}^{t_{1 f}} g_{1}\left(\mathbf{y}_{1}(t), \mathbf{u}_{1}(t), t\right) d t+\int_{t 20}^{t_{1 f}} g_{12}\left(\mathbf{y}_{1}(t), \mathbf{u}_{1}(t), \mathbf{y}_{2}(t), \mathbf{u}_{2}(t), t\right) d t \\
+\int_{t 20}^{t_{2 f}} g_{2}\left(\mathbf{y}_{2}(t), \mathbf{u}_{2}(t), t\right) d t+\phi\left(y\left(t_{f}\right)\right) \\
\dot{\mathbf{y}}(t)=\mathbf{f}(\mathbf{u}(t), \mathbf{y}(t)), \mathbf{u}(t)=\left(\mathbf{u}_{1}(t), \mathbf{u}_{2}(t)\right), \mathbf{y}(t)=\left(\mathbf{y}_{1}(t), \mathbf{y}_{2}(t)\right), \\
\mathbf{k}_{1 i}\left(\mathbf{y}_{i}, \mathbf{u}_{i}\right) \leq 0, \mathbf{k}_{2 i}\left(\mathbf{y}_{i}, \mathbf{u}_{i}\right) \geq 0, \forall t \in\left[t_{10}, t_{2 f}\right], t_{10}=0, \mathbf{y}(0)=\mathbf{y}_{0}, \mathbf{u}(0)=\mathbf{u}_{0}
\end{array}\right.
$$

where $g_{12}$ shows the aircraft coupling noise function and $J_{G 12}$ is the SEL of the two A300-aircraft.

\section{The numerical processing}

The system (4) is an optimal control problem with mixed constraints on the state and control. In order to apply the formulation of Pontryagin, we rewrite directly this system as follows:

$\left\{\begin{array}{l}\min J_{12}(y, u)=\int_{t}^{t} f(y(t), u(t), t) d t \\ \dot{y}(t)=f(y(t), u(t)) \\ k_{1}(y, u, t) \leq 0, k_{2}(y, u, t) \geq 0 .\end{array}\right.$

By considering the pseudo-Hamiltonian system (5) given by $h\left(y, u, p, p_{0}, t\right)=p^{T} f(y, u, t)-p_{0} g(y, u, t)-\mu_{1} k_{1}(y, u, t)-\mu_{2} k_{2}(y, u, t)$ where $p=\left(p_{1}, p_{2}\right)$ is the adjoint state. Thanks to this new formulation of Pontryagin, the necessary optimality conditions are given by $H_{u}\left(y, u, p, p_{0}, t\right)=0$

$\dot{y}=H_{p}\left(y, u, p, p_{0}, t\right)=f\left(y(t), u(t), \dot{p}=-H_{y}\left(y, u, p, p_{0}, t\right)\right.$

$k_{1}(y, u, t) \leq 0, k_{2}(y, u, t) \geq 0, t \in\left[t_{0}, t_{f}\right], \mu_{2} \geq 0$, where $\mathrm{H}$ is pseudo-hamilton system. By applying a symplectic portioned Runge-Kutta method for $M=(A, b), \tilde{\mu}=(\tilde{A}, \tilde{b})$ and considering the numerical stream $\xi_{h}$ : $\left(p_{n}, y_{n}\right) \rightarrow\left(p_{n+1}, y_{n+1}\right)$ If the stream is selected such that the relation $\left(\frac{\partial \xi_{h}}{\partial(p, y)}\right)^{T} \tilde{J}\left(\frac{\partial \xi_{h}}{\partial(p, y)}\right)=\tilde{J}$ is verified. The characterization of the RungeKutta symplectic method is also done using the matri $C=B \bar{A}+A^{T} \widetilde{B}-b \tilde{b}^{T} \in R^{2 s}$ when $B=\operatorname{diag}\left(b_{1}, \ldots, b_{s}\right)$ and $\tilde{B}=\operatorname{diag}\left(\tilde{b}_{1}, \ldots, \tilde{b}_{s}\right)$. 


\section{Partioned symplectic Algorithm of Runge-Kutta (SPRK) (F. Nahayo 2012)}

(1) Subdividing the interval time $\left[t_{0}, t_{f}\right]$ in $\mathrm{N}$ step $h=t_{n+1}-t_{n}=\frac{t_{f}-t_{0}}{N}, \mathrm{~N}$ is the maximum number of iteration.

(2) For $0 \leq n \leq N$,

$$
\begin{aligned}
& H_{u}\left(u_{k i}, y_{k i}, p_{k i}\right)=0 \\
& y_{n+1}=y_{n}+h \sum_{k=1}^{s} b_{k} \mathcal{H}_{p}\left(u_{n_{k}}, y_{n_{k}}\right), y\left(t_{0}\right)=y_{0}, y_{n_{k}}=y_{n}+h \sum_{j=1}^{s} a_{k j} \mathcal{H}_{p}\left(u_{n_{j}}, y_{n_{j}}\right), k=1, \ldots, s \\
& p_{n+1}=p_{n}-h \sum_{k=1}^{s} \tilde{b}_{k} \mathcal{H}_{y}\left(p_{n_{k}}, y_{n_{k}}\right), p_{N}=\phi^{\prime}\left(t_{f}\right), p_{n_{k}}=p_{n}-h \sum_{j=1}^{s} \tilde{a}_{k j} \mathcal{H}_{y}\left(p_{n_{j}}, y_{n_{j}}\right), \\
& \mathcal{H}\left(y_{n_{k}}, p_{n_{k}}\right)=H\left(\psi\left(y_{n_{k}}, p_{n_{k}}\right), y_{n_{k}}, p_{n_{k}}\right), \tilde{a}_{k j}:=b_{j}-\frac{b_{j}}{b_{k}} a_{j k}, b_{j}=\tilde{b}_{j}, k_{1}\left(y_{n}, u_{n_{k}}\right) \leq 0, \\
& k_{2}\left(y_{n}, u_{n_{k}}\right) \geq 0, \text { display } t_{n+1}, y_{n+1}, p_{n+1} .
\end{aligned}
$$

\subsection{Graphic User Interface for the Applied Mathematical Modeling Software For A Multi Aircraft Landing Dynamic system}

The user interfaces is designed in Glade and by using the GtkBuilder GTK+ object, this can be loaded by applications dynamically as needed. By using GtkBuilder, Glade XML files can be used in numerous programming languages including $\mathrm{C}, \mathrm{C}++, \mathrm{C \#}$, Vala, Java, Perl, Python, AMPL and others. Glade is Free Software released under the GNU GPL License.

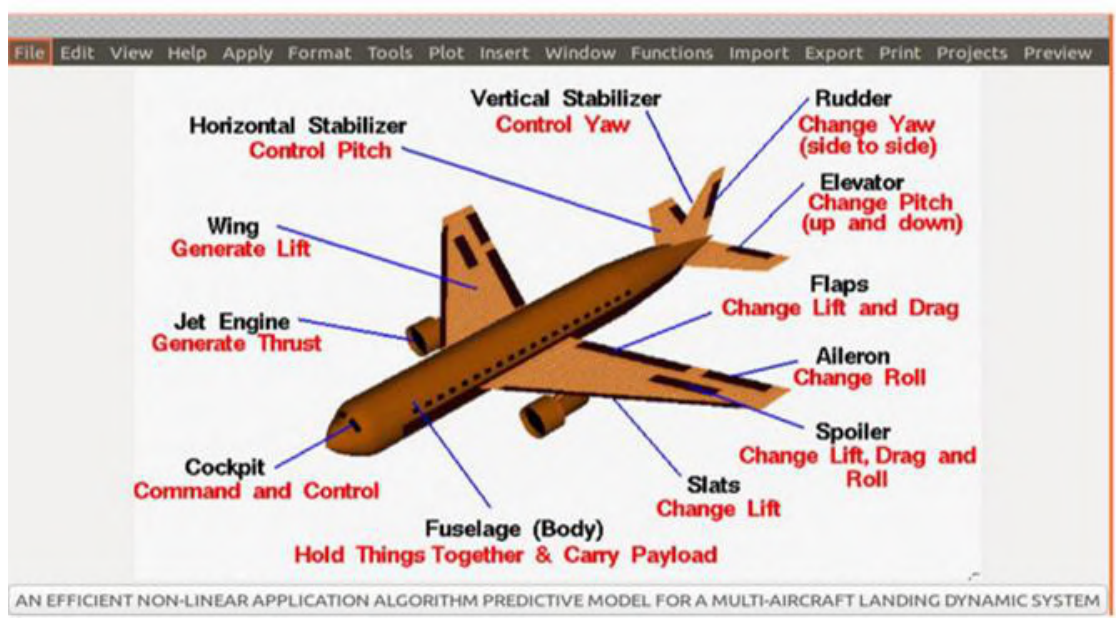

Figure 5. GNU General Public Licence AIRLADYS R2018 A A $^{+}$Graphic User Interface

Figure 1 shows AIRLADY SR2018 ${ }^{+}$Graphic User Interface and all the menu toolbar functions programmed for the running and exploitation. 


\subsection{Aircraft optimal noise levels}

Numeric results show the noise levels around airport when optimization is applied. This explains the importance of the acoustic optimization of approaching aircraft and gains brought by this model when compared with what is done daily. The observation position is considered on the ground below the path of the following way: $(-20000 \mathrm{~m},-20000 \mathrm{~m}, 0 \mathrm{~m})$ for $\mathrm{AONL}_{1},(-19800 \mathrm{~m},-19800 \mathrm{~m}, 0 \mathrm{~m})$ for $\mathrm{AONL}_{2}, \ldots,(-3200 \mathrm{~m},-3200 \mathrm{~m}, 0$ $\mathrm{m})$ to AONL8. The touchdown point on the ground is $(0 \mathrm{~m}, 0 \mathrm{~m}, 0 \mathrm{~m})$ while the temporal separation of aircraft is $90 \mathrm{~s}$. On each observation point, there is a vector of $\mathrm{N}$ noise levels as shown in discretization. It is important to consider the maximum value among the $\mathrm{N}$ values, which value shows the shortest distance between the noise source and the observation point. This result shows that the maximum noise level varies depending on observation points and decreases when the plane moves away. By comparison, This result is close to the standard jet noise values approach as shown by Harvey (H. Harvey Hubbard 1994) and (F. Nahayo and all).

\section{3. $\quad$ Aircraft Flight paths Numeric Results}

The following result are obtained with AMPL"A Mathematical Programming Modeling Language" and KNITRO.The final result precision is: Locally optimal solution found with final feasibility error $(\mathrm{abs} / \mathrm{rel})=$ $1.20 \mathrm{e}-11 / 2.19 \mathrm{e}-13$ and final optimality error $(\mathrm{abs} / \mathrm{rel})=1.69 \mathrm{e}-18 / 1.69 \mathrm{e}-$ 18.

The above figure shows the continuous descent aircraft paths. When the first plane hit the ground, the second is six hundred meters hight with a strike length of $3300 \mathrm{~m}$. This result is therefore of constraints separation when the planes are landing successively on a single track. At the end of approach, both paths coincide and follow the standard Evolution of the path constructors data by the A300 aircraft. This figure also shows the evolution of the two aircraft speeds and prove a landing because the speeds decrease from $200 \mathrm{~m} / \mathrm{s}$ up to $69 \mathrm{~m} / \mathrm{s}$ as certified by ICAO and manufacturers of aircraft. Note that the touching ground speed is $69 \mathrm{~m} / \mathrm{s}$. These trajectories obtained are similar to the standard approach values as confirmed by (S. Suzuki and all 2009). It shows correlation between aircraft flight paths and speeds. The maximum time of the approach is 600 seconds for the first aircraft and 690 seconds for the second, giving a separation time of 90 seconds. 

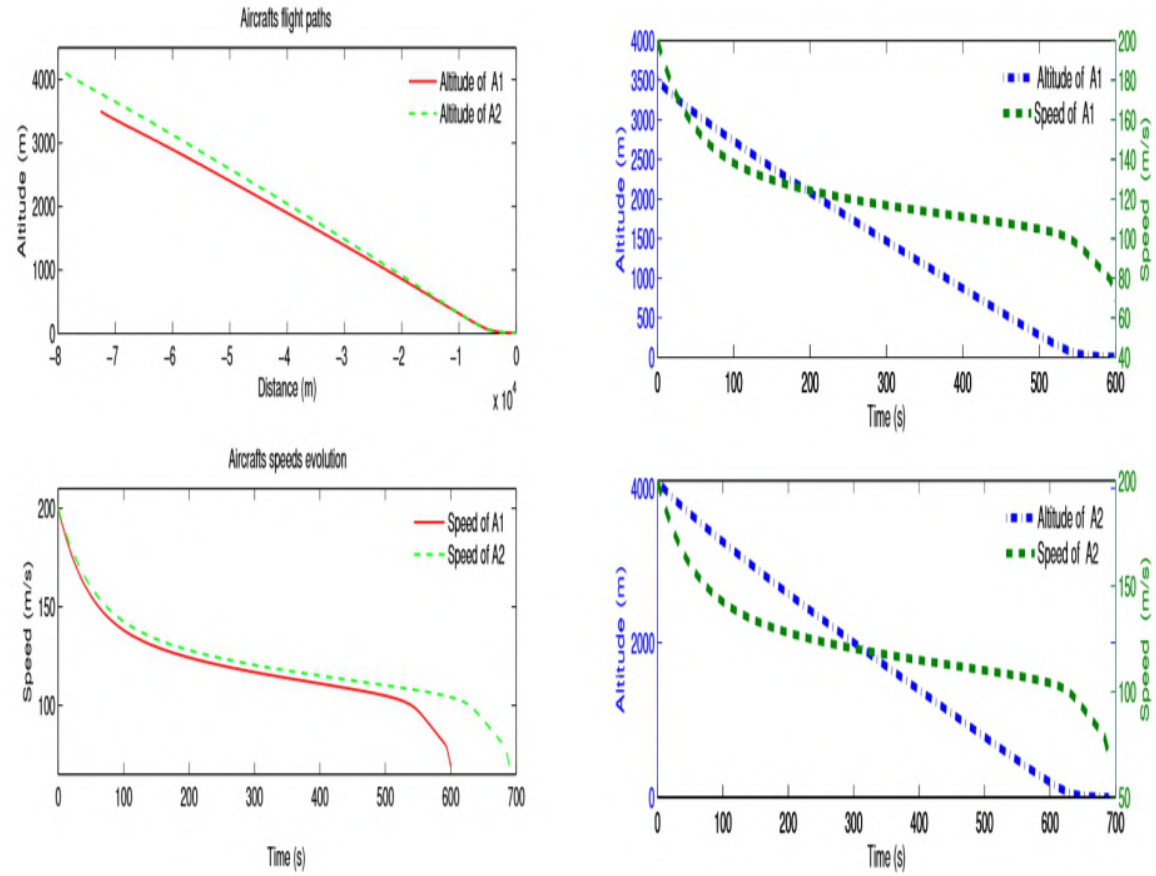

Figure 6. Two Aircraft flight paths and speeds
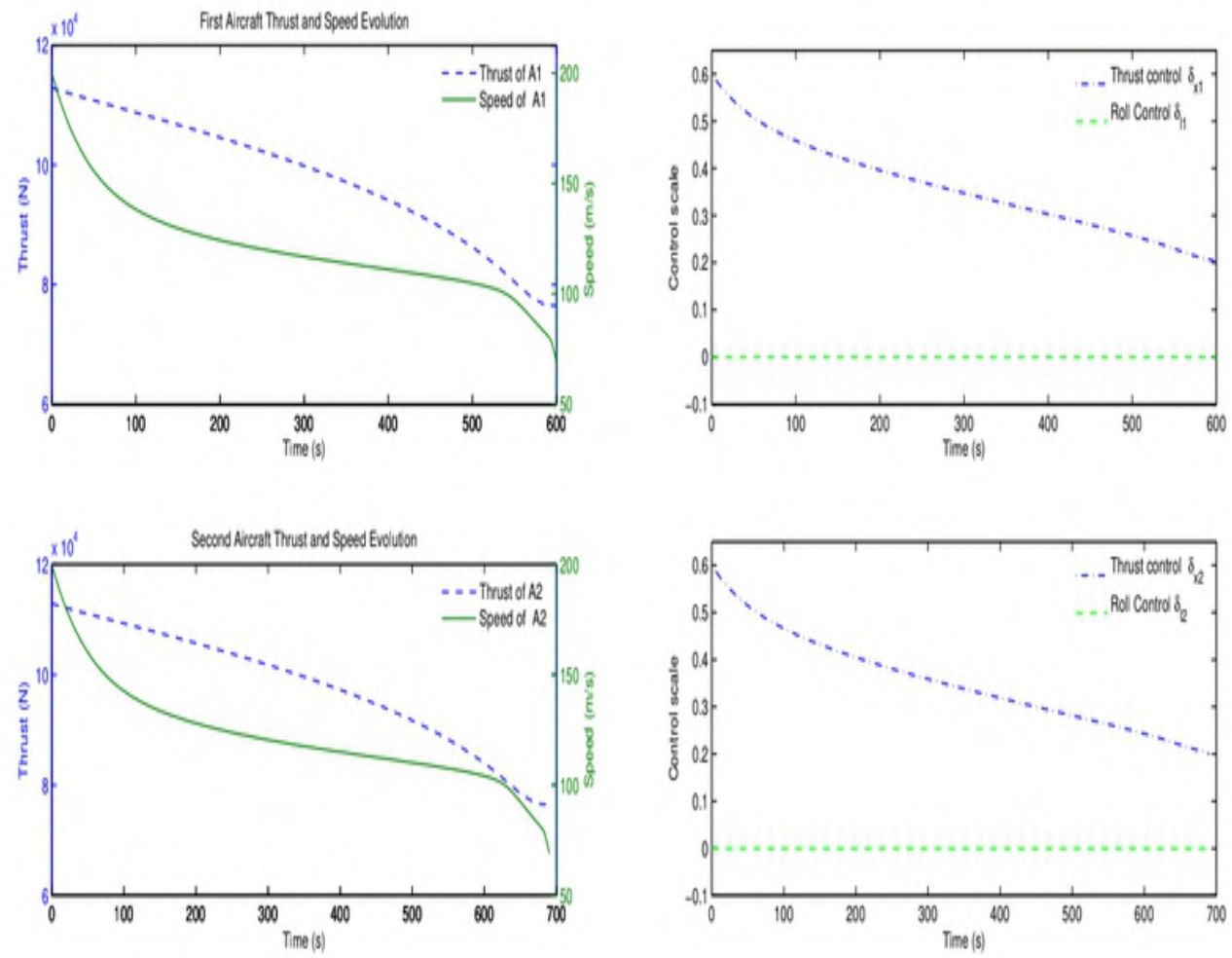

Figure 7. Comparing changes in thrust and roll control with speed of each aircraft 
The figure 7 shows a simultaneous evolution of thrust and speed for each aircraft. It is noted that the speed decreases from $200 \mathrm{~m} / \mathrm{s}$ to $69 \mathrm{~m} / \mathrm{s}$. Similarly, the thrust general trend is downward during landing. A correlation between the thrust and roll control with the speed of the two aircraft is very clarified. The figure 7 shows the thrust control and the control roll caracteristics during landing. The main control of the aircraft varies from 0.6 to 0.2 . The roll control remains zero, which proves stability of the aircraft and passengers comfort.
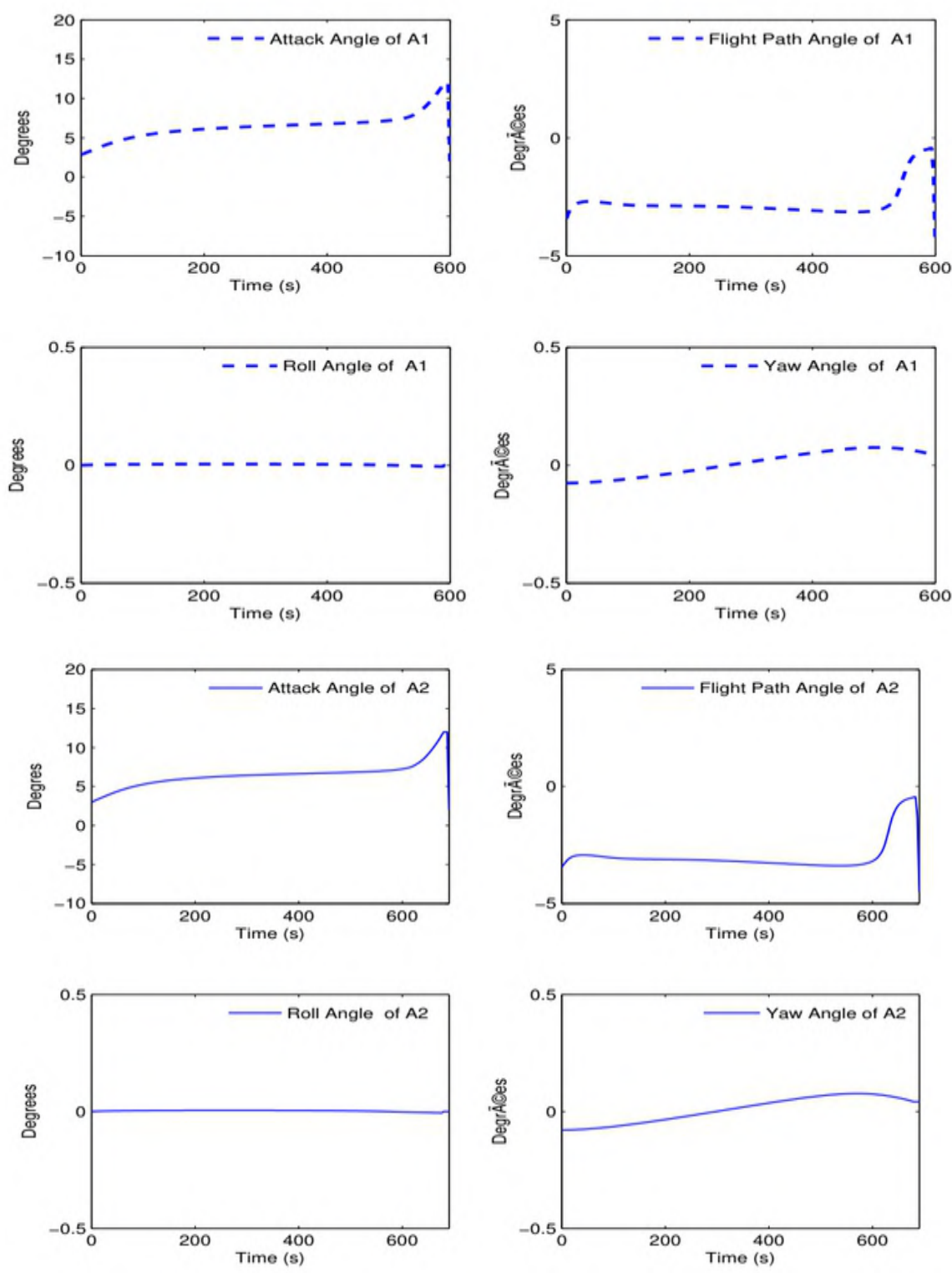

Figure 8. Evolution of aerodynamic angles of the two Aircrafts 
This figure shows the evolution of the main aerodynamic angles of the two planes. It is clear that the roll is zero while the flight angle is negative throughout the landing as recommended by ICAO in the approach procedures. The angle of attack varies between 2 and 12 degrees and the yaw angle is low because the plane is aligned to the runway.
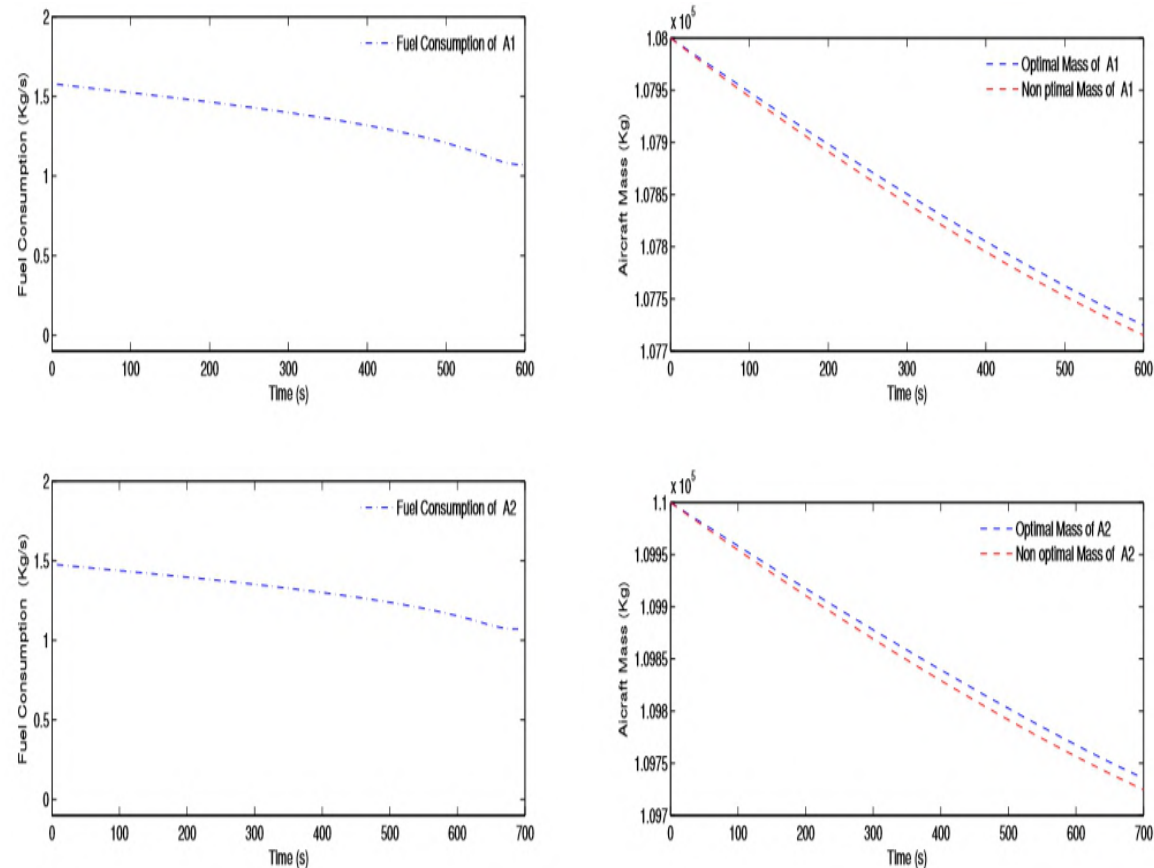

Figure 9. Evolution of kerosene usage and the optimal mass and non optimal mass of each aircraft

The figure 9 shows the evolution of the consumption of kerosene by aircraft over time. It ranges from $1.5 \mathrm{~kg} / \mathrm{s}$ to $1 \mathrm{~kg} / \mathrm{s}$ on the ground. This result is already proven by Roux (E.Roux 2005) and confirm the standars of the manufacturers of the A300 aircraft. Note that the base model operated in consumption is the Torenbeek one which has already proved its efficiency compared to other models. The figure shows the evolution of optimal and non optimal aircraft mass over time. In the first plane, the optimum mass varies from $108,000 \mathrm{~kg}$ to $107723.79176 \mathrm{~kg}$ on the ground while non optimal mass varies $108,000 \mathrm{~kg} 107714.15755 \mathrm{~kg}$. For the second plane, the optimum mass varies from $110,000 \mathrm{~kg}$ to $109734.50191 \mathrm{~kg}$ on the ground when the nonoptimal mass varies $110,000 \mathrm{~kg}$ to $109723.53824 \mathrm{~kg}$. So it clears a weight saving between $9 \mathrm{~kg}$ and $11 \mathrm{~kg}$.

\subsection{Comparison of optimal procedures and standards}

The figure comparison of aircraft optimal procedures and standards is shown by the 10 when considering the altitude and speed. It means that the 
continuous descent procedure well characterizes the optimal solution and that confirms the difference between the landing standard procedure and the landing optimal procedure. With the robust convergences characteristics, the optimal solution of the discrete problem found confirms the requirements of manufacturers and ICAO. Aircraft flight paths on the ground remains the same regardless of the particular proceedings and the slope of the path does not change as shown in (F. Nahayo 2017).
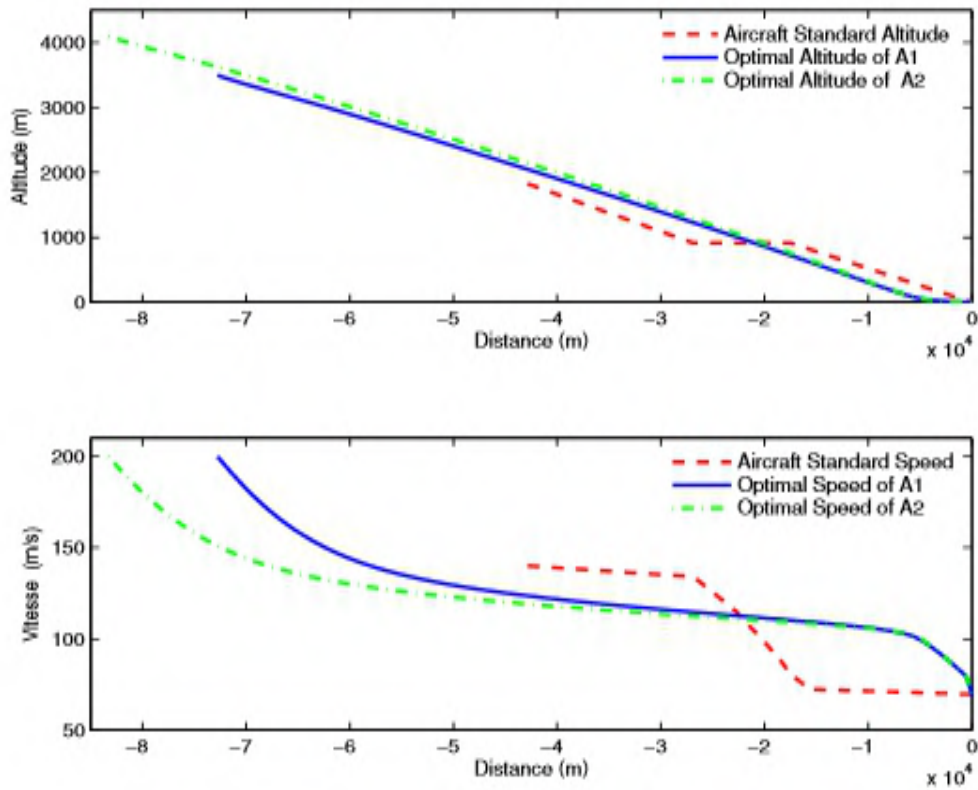

Figure 10. Comparison of optimal procedures and standards

\section{Conclusion}

In this paper, a mathematical model have been developed for noise reduction in the case of two approaching aircraft landing in succession on the same runway in Bujumbura International Airport. An algorithm for solving the optimal control problem has been developed. Theoretical considerations and practices of a direct method and the Runge-Kutta discretization scheme are used. This discretization schema is chosen because it is of sufficiently high order and it does not require computation of the partial derivatives of the system. This application had been coded with Linux system on 64 bit operating system. High runing performance are obtained with results giving feasible trajectories with a robust optimizing of the objective function. The user interfaces had been designed in Glade by using the GtkBuilder GTK+ object which can be loaded by applications dynamically as needed. By using GtkBuilder, Glade XML files can be used in numerous programming languages including $\mathrm{C}, \mathrm{C}++, \mathrm{C \#}$, Java, Perl, Python, AMPL, etc. The numerical considerations used have no limitations except the introduction of 
the constante-variables without physical interpretation in order to facilitate the resolution of the dynamic system of two aircraft. The reason is the complexity of this system, which greatly affects the nature of the Solver to use. This model can be generalized for any type of aircraft when considering real case for air traffic and airport traffic. The following process is the software both certification by Aircraft operational companies, aircraft conception companies and academicians in applied mathematics and aerospace sciences.

\section{Ackonwledgements}

This article was developed in CURMISTA/ISTA/University of Burundi and supported by the Government of Burundi through the Ministry of Higher Education and Scientific Research.

\section{References:}

1. F. Nahayo 2017, Pontryagin Principle Applied to Commercial Aircrafts Optimal Control Problem under Physical and Energetic Constraints, Gen. Math. Notes, Vol. 38, No. 1, 2017, ISSN 2219-7184; Copyright c ICSRS Publication.

2. F. Nahayo 2012, Modèle mathématique d'optimisation non-linéaire du bruit des avions commerciaux en approche sous contraintes énergétiques, Thèse de Mathématiques Appliquées de 1’UCBL I.

3. L. Abdallah 2007, Minimisation des bruits des avions commerciaux sous contraintes physique et aérodynamique, Thèse de Mathématiques Appliquées de l'UCBL I.

4. L. Abdallah, M. Haddou and S. Khardi, Optimization of operational aircraft parameters reducing noise emission, Applied Mathematical Sciences, 4, 11 (2010), 515-535.

5. K. Blin 2000,Stochastic conflict detection for air traffic management, Eurocontrol Experimental centre Publications Office, France.

6. J-L. Boiffier 1999, The Dynamics of Flight, The Equations, SUPA 'ERO (Ecole Nationale Supérieure de l'Aéronautique et de l'Espace) et ONERA-CERT, Toulouse.

7. P. Destunder, Méthodes numériques pour ingénieurs, Hermès Sciences Publications, 12-8-2010.

8. Chryssoverghi, J. Colestos and B. Kokkinis, 2007, Classical and relaxed optimization methods for optimal control problems International Mathematical Forum, No 30, pp 1477-1498.

9. P. Faurer, Analyse numérique, notes d'optimisation, Ellipses Marketing, 1998.

10. Fortin 2008, Analyse numérique pour Ingénieurs. Troisième Edition, Presses Internationales Polytechnique, ISBN 978-2-553- 01427-7. 
11. R. Fourer, D-M. Gay and B-W. Kernigham 2003, A modelling Language for Mathematical Programming, Second edition, Thomson Brooks [en ligne] disponible sur http://www.ampl.com.

12. M-M. Harris and E. Mary, How do we Describe Aircraft Noise? NASA TM - 82712, FICAN, [en ligne] disponible sur www.fican.org.

13. H. Harvey Hubbard 1994, Aeroacoustics of flight vehicles, Theory and Practices Volume 1: Noise sources and Volume 2: Noise Control. NASA Langley Research Center, Hampton, Virginia 1994.

14. Ifrance 2000, Fiches techniques, historiques et photos d'avions A300600, A300-600R, [en ligne] disponible sur http://www.ifrance.com.

15. R. James Stone \& D.E. Groesbeck\& C.L. Zola,1991, An improved prediction method for noise generated by conventional profile coaxial jets, NASA TM - 82712, AIAA-81-1991. S.Khardi F. Nahayo and M. Haddou,2011, The Trust Region Sequential Quadratic Programming Method Applied to two- Aircraft Acoustic Optimal Control Problem, Applied Mathematical Sciences, Vol.5, No.40, pp.1953-1976, ISSN 1312-885X.

16. S. Khardi 2010, Mathematical Model for Advanced CDA and Takeoff Procedures Minimizing Aircraft Environmental Impact, International mathematical Forum, vol. 5, no 36, 1747 - 1774, 2010.

17. S. Khardi 2009, Reduction of commercial aircraft noise emission around airports. A new environmental challenge,European Conference of Transport Research Institutes, vol. 1, no 4, pp 175-184.

18. R.Fourer, 2003, AMPL, A modelling Language for Mathematical Programming,B. Laboratories, http://www.ampl.com.

19. D. Martin 2000, L'Analyse des Nuisances sonores autour des aéroports, Revue technique numéro 58.

20. E. Roux 2005, Pour une approche analytique de la dynamique du vol, Thèse, SUPAERO-ONERA.

21. E. Roux 2006, Modèle de longueur de piste au décollage-atterrissage, Avions de transport civil, SUPAERO-ONERA, p 345.

22. R-A. Waltz \& T-D. Plantenga,2008, KNITRO user's Manual, Version 5.2, University of Colorado[en ligne]disponible sur http://www.ziena.com.

23. J.L. Boiffier, 2001, Dynamique de vol de l'avion, SupAéro, Départements des Aéronefs, Toulouse.

24. S. Suzuki T. Tsuchiya and A. Andreeva 2009, Trajectory Optimization for Safe, Clean and Quiet Flight,Dept. of Aeronautics and Astronautics, The University of Tokyo, ENRI International Workshop on ATM/CNS,Japan, EIWAC. 
25. H. Harvey Hubbard 1994, Aeroacoustics of flight vehicles, Theory and Practices,Volume 1: Noise sources and Volume 2: Noise Control. NASA Langley Research Center, Hampton, Virginia.

26. F. Nahayo M.Haddou S.Khardi M.Hamadiche and J.Ndimubandi 2012, Two-Aircraft optimal control problem. The in-flight noise reduction.,Journal of the European Series in Applied and Industrial Mathematics (ESAIM). Ed. EDP Sciences-ESAIM (Cambridge University Press, USA).

27. S. Khardi, F. Nahayo, and M. Haddou 2011, The Trust Region Sequential Quadratic Programming Method Applied to two- Aircraft Acoustic Optimal Control Problem, Applied Mathematical Sciences, Vol.5, No.40, pp.1953-1976, ISSN 1312-885X.

28. F. Nahayo S.Khardi J.Ndimubandi M.Haddou and M.Hamadiche 2011, Two-Aircraft Acoustic Optimal Control Problem. SQP algorithms, ARIMA, Ed. INRIA, Vol.14, pp.101-123, France.

29. F. Nahayo S. Khardi and M. Haddou 2011, Optimal control of twocommercial aircraft dynamic system during approach. The noise levels minimization, General Mathematics Notes, Vol.3 №.2.

30. M. Le Merrer 2012, Optimisation de trajectoire d'avion pour la prise en compte du bruit dans la gestion du vol, Thèse de l'ISAE, Département Onera : Commande des systèmes et dynamique du vol, SupAero, Toulouse. 